\title{
Gastroesophageal Reflux and Wheezing in Pediatry
}

\author{
pH-metry studies
}

\begin{abstract}
ALINA MIHAELA ELISEI ${ }^{1}$, DANA TUTUNARU ${ }^{1 *}$, CAMELIA ANA GRIGORE ${ }^{1}$, CIPRIAN ADRIAN DINU ${ }^{1 *}$, LAURA FLORESCU², DECEBAL VASINCU²

'Dunarea de J os University of Galati, Medicine and Pharmacy Faculty, 35 Al. I. Cuza Str., 800010, Galati, Romania, 2University of Medicine and Pharmacy Grigore T. Popa, 16 Universitatii Str. 700115, Iasi, Romania
\end{abstract}

\begin{abstract}
Analysis of esophageal $\mathrm{pH}$ is useful and recommended by specialists when the gastroesophageal reflux disease does not show specific symptoms such as chest pain or burnings, but a form of asthma and chronic cough. The investigation is performed after a mild anesthesia, inserting a thin and flexible catheter in the patient's nostril; it reaches the esophagus, particularly the esophageal sphincter that connects the stomach to the esophagus. The catheter has a sensor that monitors the acidity level, the number of reflux episodes, their duration and the part of the esophagus reached by the acid in the stomach. Gastroesophageal reflux disease is frequently met in pediatric practice, rooting in the intrauterine life, a physiologic phenomenon in infants during the first semester of life.
\end{abstract}

Keywords: esophageal reflux, respiratory diseases, pediatric practice, pH-metry, wheezing, hiatal hernia, asthma, GERD, CMPA, esophageal sphincter.

Clinical manifestations of the gastroesophageal reflux in children evolve as vomit, regurgitations, dysphagia or pyrosis (digestive manifestations); there are also atypical,extra digestive manifestations. In children, the gastroesophageal reflux is physiological in the first 3 months of life, but it disappears around 1-2 years of age. Gastroesophageal Reflux Disease is represented by all the symptoms and/or changes produced by the gastroesophageal reflux, a condition frequently met ambulatory[2].

Wheezing is a common clinical element in many children's diseases, in bronchial asthma in older children, and in acute bronchiolitis in infants. Wheezing is not shown in all patients, but there are patients with both gastroesophageal reflux and wheezing, unrelated whatsoever. As a clinical manifestation, wheezing is a highpitched noise, perceived during auscultation in the terminal phase of the exhalation, a whistling breath accompanied by the feeling of being unable to exhale the entire inspired air. Patients identified with wheezing and retrosternal burnings are referred to endoscopicassessment, while patients with wheezing alone may be subject to $\mathrm{pH}$-metry or Bernstein investigations. In specialized literature, several types of wheezing are described, namely:

-Episodic (viral) wheezing - associated with viral infections;

-Multiple trigger wheezing - with some exacerbations also between viral episodes;

-Transient wheezing - symptomatic in children up to 3 years of age, disappearing after 6 years of age;

-Persistent wheezing - symptoms can be identified also in retrospect, persisting after 6 years of age;

-Late-onset wheezing - onsets symptomatically after 3 years of age; it may be episodic or with multiple triggers.

Specialized literature also reveals that from an epidemiologic perspective, at least one third of the children may have one episode of wheezing until 3 years of age; until 6 years of age the percentage increases to $50 \%$. In preschool children, wheezing is associated with respiratory infections. The interval it shows, regardless of the cause, is age group 1-3 years[ 1,15$]$.

\section{Gastroesophageal reflux and wheezing}

There is a relation between gastroesophageal reflux and wheezing in adults, as well as in children. As children digest the food, the lower esophageal sphincter may open, allowing the content of the stomach to travel to the esophagus. Sometimes, the content of the stomach crosses the entire esophagus and the infants vomit. Other times, the content of the stomach partially raises in the esophagus, leading to burnings, respiratory disorders or leading to no symptom. Studies showed that the symptoms may be reduced after a specific treatment of gastroesophageal reflux. The treatment can also reduce the anti-asthmatic medication. The mechanism through which gastroesophageal reflux causes wheezing or even pneumonia is not known yet, but a potential mechanism might be triggered by a recurrent microaspiration or a silent aspiration that would aggress the mucosa[17]. Another cause might be that the acidity in the distal esophagus stimulates the vagally mediated reflexes by chemoreceptors and mechanoreceptors. The whistling breath (wheezing) is a symptom triggered by the narrowing or partial obturation of the airways, often a sign of asthma, but not necessarily. In order that the patient is cured from wheezing, the treatment must be targeted on the cause of the whistling breath.

\section{Relation between GERD, CMPA, and Asthma [10]}

CMPA (cow's milk protein allergy) and GERD (gastroesophageal reflux disease) have common clinical evolutions. $\mathrm{pH}$-metry investigation is necessary in CMPA as well, especially in patients with family risk. Like GERD, CMPAis often onset in infants. The clinical manifestations are complicated, with vomit, refusal of food, abdominal colic, agitation, sleep disorders, but their frequency decreases with age (through change of diet, increase and improvement of the function of the lower esophageal sphincter, acquiring tolerance to cow's milk). Atopic eczema, hives, diarrhea or constipation, wheezing, and vomit are relevant for diagnosing CMPA. Genetic arguments can be mentioned for CMPA-GERD relation, the gene responsible for severe phenotype being located on 
the short arm of 13 chromosome, close to some genes responsible for asthma and atopy[11,14]. Gastroenterological and allergological examinations revealed $42 \%$ of CMPA - GERD association. Patients with asthma are more prone to develop gastroesophageal reflux disease. $\mathrm{pH}$-metry examination revealed a prevalence of $40 \%-60 \%$ of gastroesophageal reflux and symptomatic or asymptomatic asthma in children. Despite the coexistence of these diseases, it is not clear whether it is GERD that influences the control of the asthma, or whether the asthma increases the chances to develop GERD[4-7].

\section{Diagnosis Methods}

In young ages, the respiratory symptoms and gastroesophageal reflux are common diseases, and their coexistence is also common. In children, gastroesophageal reflux disease is quite severe, for is does not show specific symptoms, a very young age overlapping the diagnosis. Infants with gastroesophageal reflux that frequently vomit are not able to gain weight or are not able to grow in a normal pace. Inflammation (esophagitis) or ulcerations (lesions) may appearin the esophagus due to the contact with the acid gastric juice. These ulcers can be painful and can bleed out, leading to anemia ( a low level of hemoglobin in blood). Narrowing of the esophagus (esophageal stricture) and Barrett's esophagus (appearance of abnormal cells in the mucosa of the esophagus) are complications that might arise in adults on long term as a result of the inflammation.In children, the instrumental and lab explorations are techniques such as radiography, scintigraphy, and echography, sensitive to $\mathrm{pH}$ change, and methods that assess the aggressive consequences of the reflux (endoscopy with harvesting and biopsy). Parents must see a doctor if the infant does not gain weight, has a general poor health condition, and is agitated. As paraclinical diagnosis methods, one may use barium radiology examination, quite unpleasant because of the taste, but effective because it points out anomalies of the esophagus, diaphragm, stomach, duodenum, and the small intestine.

Endoscopyis also a diagnosis method, performed after sedation, decreasing the discomfort. It is performed with a flexible tube with a video camera casting the image in the patient's digestive tract. It is not very effective, because it cannot detect the reflux, just its consequences, and it cannot asses the causes of the reflux.

Esophageal $\mathrm{pH}$ monitoringis the standard procedure, compulsory for diagnosing gastroesophageal reflux disease because it allows an accurate diagnosis and can estimate its evolution under treatment. Esophageal $\mathrm{pH}$ monitoring also identifies the number of refluxes within 24 hours, the duration of the longest reflux, number of refluxes that last longer than 5 minutes, medium duration and the maximum duration of the esophageal clearance, the relation between the moments in which $\mathrm{pH}$ is very acid and the clinical symptoms such as cough, regurgitation and apnea episodes. However, esophageal pH monitoring cannot diagnose the alkaline refluxes, and the data should be related to clinical symptoms and signs. For interpreting pH-metry data, Demeesler and Boix Ochoa scorings are used $[9,13]$.

Esophageal manometry assesses the esophageal motility and pressure in the lower esophageal sphincter. It is not a very sensitive method, and the assessments are done motionless or during deglutition.

The advantage of echography examination of gastroesophageal reflux in children is that it is a non- invasive method, allowing the monitorization of manifestations of the reflux.

Gastric emptying studies are performed after swallowing milk, swallowing a radioactive substance, whose itinerary is monitored, determining this way the time it took for the milk to be eliminated from the duodenum.

Esophageal clearance scintigraphy is a non-invasive method with a high degree of accuracy and reduced radioactivity. Scintigraphy can estimate the number and duration of reflux episodes, pointing out episodes of independent reflux of the $\mathrm{pH}$ of the mass subject to reflux. However, if the child does not show symptoms of gastroesophageal reflux disease, the images offered by scintigraphy are limited and cannot correlate with the tests obtained by $\mathrm{pH}$-metry.

In addition to the previously presented examinations, there are other types of clinical and paraclinical explorations, such as radiography of the thorax, blood analysis, stool test, and echography of the organs in abdominal cavity, meant to appreciate the evolution of gastroesophageal reflux in children[2, 8, 9].

\section{Symptoms and treatment of gastroesophageal reflux}

The management of esophageal reflux disease consists in controlling the symptoms and the major impact on the quality of life, while the main therapy goals are to heal the lesions, treat extra-digestive signs, prevent relapses and complications of the disease. The symptoms of gastroesophageal reflux disease in children may be difficult to identify, especially if the children are very young. In this case, the symptoms include irritability, refusal to eat, slow weight and heightgain, bending the back during or after meal. In older children, the symptoms are nausea, a feeling of burning in the esophagus, repeated regurgitation and symptoms of asthma like cough, dyspnea and weezing (whistling breath).

General measures must be applied in patients, regardless of their age, consisting in changing the lifestyle, even of infants.

In infants with functional reflux, parents should be informed that the vomit usually goes aw ay spontaneously before 1 year of age, because functional gastroesophageal reflux is benign and physiological, unlike the pathological one[14].

In older times, the infant was seated on a chair, but the pH-metry studies showed the inefficiency of the method. Sleeping with the head raised at $30^{\circ}$, on a tall pillow, can be useful atnight, diminishing the rate of the acid reflux. Reflux symptoms may be relieved or cancelled if hygienic-dietary measures that adjust the excess food or inappropriate lifestyle are followed. The parents are responsible for eliminating from their children's diet the citric juices, products based on tomatoes, chocolate, minty, fat or spicy foods, eating before going to bed, and overweight[17].

Usually, in GERD antacid medication is given, momentarily neutralizing the acidity, without curing the inflammation of the esophagus. In addition, this type of medication can provoke constipation or diarrhea. When antacid medication is unsuccessful after a few weeks, the physician may recommend medication that reduce the gastric juice production, without any side effects, also curing the inflammation of the mucosa, although it reacts slower than the antacid medication.Prokinetic medicationis also useful in the treatment of GERD strengthening the lower esophageal sphincter, emptying the stomach faster, and tightening the valve between the stomach and the esophagus[16-19, 21]. 
When medication is not successful, surgery is recommended, particularly Nissen fundoplication, through which the upper part of the stomach is wrapped around the external part of the lower esophagus. The surgical intervention is recommended in children and young patients to avoid long term intake of drugs[3,12,13,20-22].

Overall, GERD manifests itself by anemia and the treatmentis stopped when the child starts developing well, does not vomit any longer, gains weight, and the anemia is corrected.

\section{Conclusions}

Gastroesophageal reflux physiologically appears in approximately $70 \%$ of infants, normally disappearing until 1 year of age, and it is pathologic if it persists after 18-24 months, when it develops complications. Gastroesophageal reflux disease is found in $59 \%$ males, more than in females. The most frequent complication of the gastroesophageal reflux is esophagitis, whose treatment must last 1-3 months, supplemented by protective medication for the mucosa in infants, together with a measure for lowering the acidity like proton pump inhibitors. $15 \%$ of the studied patients with esophageal reflux disease also suffer from wheezing. The surgical treatment is indicated only when patients do notrespond to medication, and the gastroesophageal reflux is maintained by factors like hiatal hernia or certain anatomical defects. Esophageal pH-metry helps making the difference between physiological and pathological gastroesophageal reflux.

\section{References}

1.BRAND P.L.P., BARALDI E., BISGAARD H., BONER AL., CASTRORODRIGUEZ JA. and al. Definition, assessment and treatment of wheezing disorders in preschool children: an evidence-based approach. EurRespir J, 2008, pg. 32: 1096-1110.

2.BURLEA M., LUPU V. V., Etiopatogenia bolii de reflux gastroesofagian. Revista românã de pediatrie - no. 3, 2010

3.BURLEA M., LUPU V. V., Diaconescu S., Tratamentul bolii de reflux gastroesofagian la copil. Revista românã de pediatrie - vol. 59, no. 4, 2010

4.CHEN M.Y.M., GELFOND D.W., Reflux evaluation: correlation between $\mathrm{pH}$ results: esophagitis, esophageal dismotility - Dis Esophagus 12: 4:303-306

5.CONDINO A. ADRIA, SONDHEIMER JUDITH, Evaluation of Gastroesophageal Reflux in Pediatric Patients with Asthma using Impedance-pH Monitoring, J Pediatr 2006; 149:216-9

6.CONSTANTINIDE PAULA, BURLEA MARIN, LUPU V., Relaia alergie alimentarã - boala de reflux gastroesofagian la sugar, Revista romana de pediatrie - vol. LX, no. 4, 2011

7.DONELLY J. RAYMUND, BERRISFORD G. RICHARD, TRAN A. JANE, Simultaneous Tracheal and Esophageal pH Monitoring: Investigating Reflux-Associated Asthma, The Society of Thoracic Surgeons, 1993 8.GILSON SHARON, Causes of Gastroesophageal Reflux Diseas. About.com Guide, Updated February 24, 2010.
9.GORENSTEIN ARKADI, LEVINE ARIE, Severity of Acid Gastroesophageal Reflux Assessed by pH Metry: Is it associated with Respiratory Disease?, Pediatric Pulmonology 36:330-334 (2003), WileyLiss, Inc. 2003

10.HURDUC V., DRAGOMIR D., MANDA A., DAVITOIU A. M., Refluxul gastro esofagian si astmul bronsic la copil, Revista romana de pediatrie, vol. 56, no. 1, 49-55, 2007

11.MC CALLISTER WJ, PARSONS JP, MASTRONARDE J G., The relationship between gastroesophageal reflux and asthma: an update TherAdvRespir Dis, April 2011 5: 143-150.

12.RAFFERTY G, MAINIE I, McGARVEY L.P.A., Respiratory and laryngeal symptoms secondary to gastro-oesophageal reflux, Frontline Gastroenterol 2011;2:212- 217.

13.RAMAIAH N. RAGHU, STEVENSON MICHAEL, Hypopharyngeal and distal esophageal $\mathrm{pH}$ monitoring in children with gastroesophageal reflux and respiratory symptoms, J ournal of Pediatric Surgery (2005) 40, 1557-1561, Elsevier, 2005

14.RAFTU, G, MITREA, G, MACOVEI, LA, NECHITA, A. Chemical Additives from the Composition of Plastic Products and Other Materials in Establishing Diagnosis for Alergy Disease. MATERIALE PLASTICE, 2018, 55(4): 609-612.

15.ROGERS LINDA, Role of sleep apnea and gastroesophageal reflux in severe asthma, p. 462-463, Elsevier Inc., 2016

16.SACCO OLIVIERO, SILVESTRI MICHELA, GHEZZI MICHELE, Airway inflammation and injury in children with prevalent weakly acidic gastroesophageal refluxes, Respiratory Medicine, 143 (2018) 42-47, Elsevier, 2018

17.FLORESCU, L, TEMNEANU, OR, MINDRU, DE. Social and Medical Implications of Teenage Motherhood. REVISTA DE CERCETARE SI INTERVENIE SOCIALÃ 52, 2016, pp. 80-91

18.MINDRU, DE, STANESCU, RS, MATEI, MC, DUCEAC, LD, RUGINA, A, TEMNEANU, OR, UNGUREANU, M, FLORESCU L., Stress in pediatric patients - the effect of prolonged hospitalization. MEDICAL-SURGICAL JOURNAL - REVISTA MEDICO-CHIRURGICALA, 120, 2016, no.2, pp. 417-423.

19.MINDRU, DE, MATEI, MC, RUGINA, A, CIOMAGA, IM, NISTOR, N, FLORESCU, $L$. The informed consent in pediatrics - a child's right. MEDICAL-SURGICAL JOURNAL - REVISTA MEDICO-CHIRURGICALA, 123, 2019, no.1, pp.153-160.

20.SLOAD L. RYAN, BRIGGER T. MATTHEW, Surgery for reflux induced airway disease: A systematic review, International J ournal of Pediatric Otorhinolaryngology 78 (2014) 1211-1215, Elsevier, 2014.

21.LUCA, AC, DUCEAC, LD, MITREA, G, CIUHODARU, MI, ICHIM, DL, BACIU, G, BANU, EA, IORDACHE, AC. Antibiotic Encapsulated Nanomaterials with Application in Medical Area., Mat. Plast., 55, 2018, no.4, p. 552-554.

22.STOICESCU P, PLESCA D. Wheezing-ulrecurent la copilul $\mathrm{cu}$ vârstamai mica de 6 ani. www.medability.ro., www.medability.ro/pdf/ wheezingul_recurent.pdf., 2009.

Manuscript received:17.10.2018 